\title{
The Frequency of Antidepressant Medication Use in Patients with Type 2 Diabetes Mellitus
}

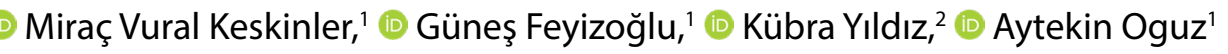 \\ 'Department of Internal Medicine, Istanbul Medeniyet University Faculty of Medicine, Istanbul, Turkey \\ ${ }^{2}$ Department of Nutrition and Dietetics, Istanbul Medeniyet University Faculty of Health Sciences, Istanbul, Turkey
}

\section{ABSTRACT}

Objectives: To determine the rates of antidepressant drug usage and its associated factors in patients with type 2 diabetes mellitus (DM).

Methods: Patients with type 2 DM between the ages of 18 and 85 years who were followed-up in the DM outpatient clinic of a university hospital between May and September 2019 were included. The data of patients were analyzed retrospectively and age, duration of DM, comorbid diseases, information on smoking, anthropometric measurements such as, height and weight and antidepressant drug use were assessed from the hospital system. Also, the patients were assesed about their application to the psychiatry clinic and whether or not they were using any antidepressant drug.

Results: The study included 463 patients with type 2 DM and 24 (68.6\%) of the patients were female. It was found that $56(12.1 \%)$ of the patients applied to the psychiatry outpatient clinic in the last three years and $23(41.1 \%)$ of these patients used antidepressant medication. Patients who did not apply to the psychiatry outpatient clinic were also found to be using antidepressant drugs, accounting for $48(11.8 \%)$ of all patients. Forty-eight (67.7\%) of the antidepressant drug users were female and $23(32.3 \%)$ were male $(p=0.002)$. Median body mass index was $32.4(24.6-45.9) \mathrm{kg} / \mathrm{m}^{2}$ in antidepressant drug users and $30.3(19.0-52.0) \mathrm{kg} / \mathrm{m}^{2}$ in nonusers $(p=0.024)$.

Conclusion: The frequency of antidepressant use in DM patients is quite common, depression and type 2 DM are intertwined diseases.

Keywords: Antidepressive agents, depression, diabetes mellitus

Address for correspondence: Dr. Miraç Vural Keskinler. Department of Internal Medicine, Istanbul Medeniyet University Faculty of Medicine, Istanbul, Turkey

Phone: +90 5052733714

E-mail:miracvural@hotmail.com

Received Date: 07.09.2020

Accepted Date: 04.01.2021

Published online: 10.03.2021

@Copyright 2021 by Anatolian Journal of Family Medicine -

Available online at www.anatoljfm.org

OPEN ACCESS

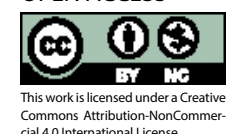

Commons Attribution-Noncomm
cial 4.0 Interatiotional License

\section{INTRODUCTION}

Antidepressant drugs are among the most prescribed drugs worldwide. ${ }^{[1]}$ The $160 \%$ increase in the use of antidepressant drugs in Turkey over the last decade is quite remarkable. ${ }^{[2]}$ This group of drugs is frequently prescribed by both psychiatry and internal medicine specialists. In particular, antidepressant medication use is more common in patients with chronic diseases, such as diabetes mellitus (DM). Depression is present in one out of every four patients with type $2 \mathrm{DM}$, and on the other hand, depression also increases the risk of developing $\mathrm{DM}^{\left[{ }^{[3]}\right.}$ Type 2 DM typically occurs in those who are overweight or obese. Individuals with type 2 DM are significantly more likely than age-matched controls to be disabled, incapacitated, or unemployed. ${ }^{[4]}$ In the study conducted by Semenkovich et al., it was shown that individuals newly diagnosed with type $2 \mathrm{DM}$ were also diagnosed with depression $30 \%$ more commonly in the last three years compared to controls without DM..$^{[5]}$

This study aimed to determine the rates of antidepressant drug use in patients who applied to the DM outpatient clinic. 


\section{METHOD}

This study included patients aged 18-85 years who had type 2 DM followed-up in the DM outpatient clinic between May and September 2019. Of the 800 patients with files, $463(57.8 \%)$ patients with complete data were included. The data of these patients for the last three years were examined retrospectively and anthropometric measurements such as height, weight and waist circumference were assessed. Height was measured using a tape measure that does not stretch by breathing deeply, while the individual was in an up right position, on the head Frankfurt plane, feet were adjacent to the heels, back, and hips, and the heels touched the wall. Body weight was measured with bioelectrical impedance analysis (Tanita TBF $300 \mathrm{M}$, Tokyo-Japan). Body mass index (BMI) was calculated by dividing the body weights of the individuals by the square of their height in meters. Also, age, DM duration, comorbidities, smoking status, antidepressant drug use, and laboratory measurements were assessed in the files of patients. Venous blood samples from the patients were studied device using the High-performance liquid chromatography method (A Tosoh HLC-723 G8, Tosoh, Japan).

From the hospital system, the patients were asked about their application status to the psychiatry clinic and whether they used any antidepressant drug. The research data were filled independently in a suitable environment by the patients who agreed to participate in the study after being informed about the study.

Power analysis was calculated using the G-Power program. With an unequal sample size of approximately $1: 5.5$, a statistical power of $98.6 \%$ was achieved with a 0.05 a error and an effect size of 0.5 . Patients who could not speak Turkish and had incomplete file records were excluded in the study.

The SPSS ver. 25 software was used for the statistical analyses. In the analysis of the study data, descriptive statistical methods including mean, standard deviation, median, minimum, and maximum were used in the comparison of the continuous variables. For categorical variables, descriptive statistical methods were calculated by frequency and percentage. Student's t-test was used for comparing two groups of normally distributed variables and Mann Whitney $\mathrm{U}$ test was used for comparing two groups of the nonnormally distributed variables. Additionally, Chi-square test was used to compare two categorical variables. A p value $<0.05$ was considered statistically significant.

\section{RESULTS}

Four hundred and sixty-three patients were included in this study. The mean BMI was $32.4(24.6-45.9) \mathrm{kg} / \mathrm{m}^{2}$ in the antidepressant drug using group and $30.3(19.0-52.0) \mathrm{kg} /$ $\mathrm{m}^{2}$ in the non-users group $(\mathrm{p}=0.024)$. Fifteen $(27.3 \%)$ of the patients with coronary artery disease were using antidepressant drugs. The factors affecting use of antidepressant drugs in patients with DM are summarized in Table 1.

When the psychiatry outpatient clinic application status was examined, it was observed that of the 56 (12.1\%) patients consulted to the psychiatry outpatient clinic in the last three years, 39 (69.6\%) were women, and 17 (30.4\%) were men $(p=0.431)$. Among 407 patients, 48 (11.8\%) patients were using antidepressant medications without a psychiatrist's prescription. The referral rates to the psychiatry outpatient clinic according to the $\mathrm{HbA1c}$ levels of the patients were compared. The rate of referring to the psychiatry outpatient clinic was 105 (9.5\%) with $\mathrm{HbA} 1 \mathrm{c}<7 \%$, while the rate of referring to the psychiatry outpatient clinic was $358(12.8 \%)$ in patients with $\mathrm{HbA} 1 \mathrm{c} \geq 7 \%$. The application to psychiatry outpatient clinic in patients with DM and the related factors are summarized in Table 2.

\section{DISCUSSION}

It has always been debated whether DM causes depression or depression causes DM. In the 1600s, Dr. Thomas Willis argued that DM occurs mostly in individuals who experience stress and are sad. ${ }^{[6]}$ On the other hand, it is obvious that the complications and comorbid conditions accompanying type $2 \mathrm{DM}$ are an important factor that leads to depression. There are studies showing that the use of antidepressant drugs, especially tricyclic antidepressant drugs and selective serotonin reuptake inhibitors, increase weight gain and indirectly, the risk of DM. ${ }^{[7,8]}$ The World Health Organization adverse drug reaction database states that these effects of antidepressant drugs occur especially after 1 year. ${ }^{[9]}$ The usage of antidepressant drugs in patients with DM and the related factors were examined in this study.

The use of antidepressant drugs in patients with type 2 DM who applied to the DM and psychiatric outpatient clinics was assessed in this study. It was observed that antidepressant drugs usage was more frequent among women than men in patients with DM. Gender difference in antidepressant drug use was reported in large scale population-based cohort studies. ${ }^{[10]}$ This may be related with the possibility of higher depression frequency in women. ${ }^{[11]}$ Over treatment of women or under treatment of men with antidepressant drugs may also be another possibility. ${ }^{[12]}$ Although application to psychiatry clinics was statistically insignificant in our patient group, it was higher in females than males.

BMI was higher among DM patients who used antidepressant drugs. The reason why the BMI measurements of the 


\section{Table 1. The factors affecting use of antidepressant drugs in patients with diabetes mellitus}

\begin{tabular}{|c|c|c|c|}
\hline & \multicolumn{2}{|c|}{$\begin{array}{c}\text { Use of antidepressant } \\
\text { drugs }\end{array}$} & \multirow[b]{2}{*}{$\mathbf{p}$} \\
\hline & Yes $(n=71)$ & No $(n=392)$ & \\
\hline \multicolumn{4}{|l|}{ Gender } \\
\hline Female & $48(67.7)$ & $207(52.8)$ & $0.002^{*}$ \\
\hline Male & $23(32.3)$ & $185(47.2)$ & \\
\hline Age (years) & $63.0(41.0-85.0)$ & $61.0(23.0-88.0)$ & $0.533^{+}$ \\
\hline Duration of DM (years) & $7.0(1.0-30.0)$ & $7.5(1.0-30.0)$ & $0.270^{+}$ \\
\hline BMI $\left(\mathrm{kg} / \mathrm{m}^{2}\right)$ & $32.4(24.6-45.9)$ & $30.3(19.0-52.0)$ & $0.024^{\dagger}$ \\
\hline Waist circumference $(\mathrm{cm})$ & $104.2 \pm 10.9$ & $102.0 \pm 11.4$ & $0.122^{\ddagger}$ \\
\hline $\mathrm{HbA1c}(\%)$ & $7.8(5.6-17.8)$ & $8.2(5.0-16.4)$ & $0.480^{+}$ \\
\hline \multicolumn{4}{|l|}{ HbA1c level groups } \\
\hline $\mathrm{HbA} 1 \mathrm{c}<7 \%$ & $16(22.5)$ & $89(22.7)$ & $0.975^{*}$ \\
\hline $\mathrm{HbA} 1 \mathrm{c} \geq 7 \%$ & $55(77.5)$ & $303(77.3)$ & \\
\hline Smoking & $11(12.8)$ & $75(87.2)$ & $0.462^{*}$ \\
\hline Alcohol use & $3(8.6)$ & $32(91.4)$ & $0.244^{*}$ \\
\hline \multicolumn{4}{|l|}{ Comorbidities } \\
\hline Hypertension & 49 (17.9) & $224(82.1)$ & $0.063^{*}$ \\
\hline Dyslipidemia & $48(17.5)$ & $226(82.5)$ & $0.041^{*}$ \\
\hline CAD & $15(27.3)$ & $40(72.7)$ & $0.398^{*}$ \\
\hline COPD & $1(10.0)$ & $9(90.0)$ & $0.532^{*}$ \\
\hline Hypothyroidism & $4(14.8)$ & $23(85.2)$ & $0.601^{*}$ \\
\hline \multirow{2}{*}{\multicolumn{4}{|c|}{$\begin{array}{l}\text { BMI: Body mass index; CAD: Coronary artery disease; COPD: Chronic obstructive pulmonary; DM: Diabetes mellitus. } \\
\text { Data is expressed as } n(\%) \text {, mean } \pm \text { standard deviation, median (minimum-maximum). }\end{array}$}} \\
\hline & & & \\
\hline${ }^{*} \mathrm{Chi}$-square test, ${ }^{\dagger}$ Mann-Whit & t, ' Student's t test. & & \\
\hline
\end{tabular}

patients using antidepressant drugs were higher than that of the non-users may be due to the fact that the depression causes demotivation to support life style modifications and decrease diet compliance. On the other hand, this result may have been seen due to the metabolic effects of antidepressant drugs. ${ }^{[13]}$

The frequency of depression and rates of antidepressant drug usage increase with the deterioration of the regulation in DM. ${ }^{[14]}$ In our study, no difference was found between the groups with $\mathrm{HbA} 1 \mathrm{c} \geq 7 \%$ and $\mathrm{HbA} 1 \mathrm{c}<7 \%$ in terms of using antidepressant drugs or going to the psychiatry outpatient clinic. The rate of referral to the psychiatry outpatient clinic was $12.8 \%$ in the group whose blood glucose regulation was relatively poor.

Among patients with coronary artery disease (CAD), antidepressant drug usage rate was higher than in the other comorbidities groups. In the literature, patients with CAD who had acute cardiac events and those with untreated depression have an impaired quality of life, increased mortality risk, were less likely to participate in cardiac rehabilita- tion, and the risk of new cardiovascular events was higher. ${ }^{[15]}$ May et al. analyzed data from 24137 patients who were diagnosed with CAD by angiography between 1993 and 2016 , and $15 \%$ of these patients were diagnosed with depression. ${ }^{[16]}$

Another important result in our study was that $11.8 \%$ of all groups were using antidepressant drugs without any application to the psychiatry clinics, although reimbursement for antidepressant drugs in our country is only possible with the consent of a psychiatry or neurology specialists. This result is more striking if their rate in the total number of patients using antidepressant medications is considered.

Regarding the limitations of our study, no depression scale was applied to our patients, and depression diagnosis and medication use were recorded according to the patient's statement and International Statistical Classification of Diseases and Related Health Problems Code. The active ingredients of the antidepressant drugs used by the patients are unknown. 


\begin{tabular}{|c|c|c|c|}
\hline & \multicolumn{2}{|c|}{$\begin{array}{l}\text { Application to psychiatry } \\
\text { outpatient clinic }\end{array}$} & \multirow[b]{2}{*}{$\mathbf{p}$} \\
\hline & Yes $(n=56)$ & No $(n=407)$ & \\
\hline \multicolumn{4}{|l|}{ Gender } \\
\hline Female & 39 (69.6) & $216(53.1)$ & $0.431^{*}$ \\
\hline Male & $17(30.4)$ & 191(46.9) & \\
\hline Age (years) & $62.5(35.0-81.0)$ & $61.0(23.0-88.0)$ & $0.291^{+}$ \\
\hline Duration of DM (years) & $7.0(1.0-30.0)$ & $7.0(1.0-30.0)$ & $0.022^{+}$ \\
\hline BMI $\left(\mathrm{kg} / \mathrm{m}^{2}\right)$ & $30.5(24.6-49.5)$ & $30.4(19.0-52.0)$ & $0.254^{\dagger}$ \\
\hline Waist circumference $(\mathrm{cm})$ & $101.5 \pm 9.9$ & $102.4 \pm 11.5$ & $0.550^{\ddagger}$ \\
\hline $\mathrm{HbA1c}(\%)$ & $7.9(5.7-15.2)$ & $8.2(5.0-17.8)$ & $0.062^{+}$ \\
\hline \multicolumn{4}{|l|}{$\mathrm{HbA1c}$ level groups } \\
\hline $\mathrm{HbA} 1 \mathrm{c}<7 \%$ & $10(17.9)$ & $95(23.3)$ & $0.975^{*}$ \\
\hline $\mathrm{HbA} 1 \mathrm{c} \geq 7 \%$ & $46(82.1)$ & $312(76.7)$ & \\
\hline Smoking & $6(7.0)$ & $80(93.0)$ & $0.104^{*}$ \\
\hline Alcohol use & $5(14.3)$ & $30(85.7)$ & $0.594^{*}$ \\
\hline \multicolumn{4}{|l|}{ Comorbidities } \\
\hline Hypertension & $39(14.3)$ & $234(85.7)$ & $0.089^{*}$ \\
\hline Dyslipidemia & $41(15.0)$ & $231(85.0)$ & $0.540^{*}$ \\
\hline CAD & $10(18.2)$ & $45(81.8)$ & $0.140^{*}$ \\
\hline COPD & $0(0.0)$ & $10(100)$ & $0.611^{*}$ \\
\hline Hypothyroidism & $7(25.9)$ & $20(74.1)$ & $0.023^{*}$ \\
\hline \multicolumn{4}{|c|}{$\begin{array}{l}\text { BMI: Body mass index; CAD: Coronary artery disease; COPD: Chronic obstructive pulmonary; DM: Diabetes mellitus } \\
\text { Data is expressed as } n(\%), \text { mean } \pm \text { standard deviation, median (minimum-maximum). } \\
{ }^{*} \text { Chi-square test, }{ }^{\dagger} \text { Mann-Whitney U test, }{ }^{\ddagger} \text { Student's t test. }\end{array}$} \\
\hline
\end{tabular}

\section{CONCLUSION}

Most of the patients using antidepressant drugs in our DM patients were taking these drugs without applying to a psychiatry clinic. There was no relationship between antidepressant drug use and DM control. In order to prevent complications in DM, a holistic approach to patients is recommended by guidelines. In this holistic approach, psychiatric disorders should definitely be taken into consideration and DM management should be done in cooperation with psychiatrists and psychologist when necessary.

\section{Disclosures}

Peer-review: Externally peer-reviewed.

Conflict of Interest: None declared.

Ethics Committee Approval: The study was approved by the Ethics Committee of Istanbul Medeniyet University, Göztepe Training and Research Hospital (Approval date: May 18, 2020 and Approval number: 2020).
Authorship Contributions: Concept: M.V.K.; Design: M.V.K., A.O.; Supervision: M.V.K., A.O., Materials: M.V.K.; Data: M.V.K, G.F.; Analysis: G.F Literature search: M.V.K., Writing: M.V.K., G.F, K.Y.; Critical revision: A.O.

\section{REFERENCES}

1. Olfson M, Marcus SC. National patterns in antidepressant medication treatment. Arch Gen Psychiatry 2009;66(8):84856. [CrossRef]

2. Aydın N, Çetin M, Kurt E, Savaş H, Açıkel C, Kılıç S et al. Psikofarmakoloji derneği Türkiye'de psikotrop ilaç tüketimi ve mevcut uygulamaların tıbbi, etik ve ekonomik sonuçları raporu. Klinik Psikofarmakol Bülteni 2013;23:390-402. [CrossRef]

3. WHO: the global burden of disease: 2004 update. Available at: https://www.who.int/healthinfo/global_burden_disease/2004_ report_update/en/\#: :text=A\%20response\%20to\%20the\%20 need,health\%20of\%20the\%20world's\%20population. Accessed Mar 8, 2021.

4. Okoro CA, Denny CH, Greenlund KJ, Benjamin SM, Strine TW, 
Balluz LS, et al. Risk factors for heart disease and stroke among diabetic persons, by disability status. J Diabetes Complications 2005;19(4):201-6. [CrossRef]

5. Semenkovich K, Brown ME, Svrakic DM, Lutsman PJ. Depression in type 2 diabetes mellitus: prevalence, impact, and treatment. Drugs 2015;75:577-87. [CrossRef]

6. Willis T. Pharmaceutice rationalis sive diatriba de medicamentorum operationibus in humano corpore. 4th ed. Oxford: $E$ Theatro Sheldoniano; 1678. p. 128-9.

7. Pan A, Sun Q, Okereke OI, Rexrode KM, Rubin RR, Lucas M, et al. Use of antidepressant medication and risk of type 2 diabetes: results from three cohorts of US adults. Diabetologia 2012;55(1):63-72. [CrossRef]

8. Andersohn F, Schade R, Suissa S, Garbe E. Long-term use of antidepressants for depressive disorders and the risk of diabetes mellitus. Am J Psychiatry 2009;166(5):591-8. [CrossRef]

9. Bate $A$, Lindquist $M$, Edwards IR, Orre R. A data mining approach for signal detection and analysis. Drug Saf 2002;25(6):393-7.

10. Brody DJ, Gu Q. Antidepressant use among adults: United States, 2015-2018. NCHS Data Brief 2020;377:1-8

11. Albert PR. Why is depression more prevalent in women? J Psy- chiatry Neurosci 2015;40(4):219-21. [CrossRef]

12. Thunander Sundbom L, Bingefors K, Hedborg K, Isacson D. Are men under-treated and women over-treated with antidepressants? Findings from a cross-sectional survey in Sweden. BJPsych Bull 2017;41(3):145-50. [CrossRef]

13. Katon W, Cantrell CR, Sokol MC, Chiao E, Gdovin JM. Impact of antidepressant drug adherence on comorbid medication use and resource utilization. Arch Intern Med 2005;165(21):2497503. [CrossRef]

14. Shehatah A, Rabie MA, Al-Shahry A. Prevalence and correlates of depressive disorders in elderly with type 2 diabetes in primary health care settings. J Affect Disord 2010;123(1-3):197201. [CrossRef]

15. Pragle AS, Salahshor S. Identifying and managing depression in patients with coronary artery disease. JAAPA 2018;31(5):128. [CrossRef]

16. May HT, Horne BD, Knight S, Knowlton KU, Bair TL, Lappé DL, et al. The association of depression at any time to the risk of death following coronary artery disease diagnosis. Eur Heart J Qual Care Clin Outcomes 2017;3(4):296-302. [CrossRef] 